\title{
Protonation of the $\mathrm{N}_{2}$-reduction catalyst [HIPTN $\left.{ }_{3} \mathrm{~N}\right] \mathrm{Mo}$ (III) investigated by ENDOR spectroscopy
}

\author{
R. Adam Kinney ${ }^{\dagger}$, Rebecca L. McNaughton ${ }^{\dagger}$, Jia Min Chin ${ }^{\ddagger}$, Richard R. Schrock ${ }^{\ddagger}$, and Brian \\ M. Hoffman ${ }^{\dagger}$ \\ tDepartment of Chemistry, Northwestern University, Evanston, Illinois 60208 \\ ¥Department of Chemistry, Massachusetts Institute of Technology, Cambridge, Massachusetts \\ 02139
}

\section{Abstract}

Dinitrogen is reduced to ammonia by the molybdenum complex of $\mathrm{L}=\left[\mathrm{HIPTN}_{3} \mathrm{~N}\right]^{3-}(\mathbf{M o})$. The mechanism by which this occurs involves stepwise addition of proton/electron pairs, but how the first pair converts $\mathbf{M o N}_{2}$ to Mo-N=NH remains uncertain. The first proton of reduction might bind either at $\mathrm{N}_{\beta}$ of $\mathrm{N}_{2}$ or at one of the three amido nitrogen $\left(\mathrm{N}_{\mathrm{am}}\right)$ ligands. Treatment of MoCO with $\left[2,4,6-\mathrm{Me}_{3} \mathrm{C}_{5} \mathrm{H}_{3} \mathrm{~N}\right] \mathrm{BAr}_{4}\left(\mathrm{Ar}{ }^{\prime}=2,3-\left(\mathrm{CF}_{3}\right)_{2} \mathrm{C}_{6} \mathrm{H}_{3}\right)$ in the absence of reductant generates $\mathrm{HMoCO}^{+}$, whose EPR spectrum has greatly reduced g-anisotropy relative to MoCO. ${ }^{2} \mathrm{H}$ Mims pulsed electron-nuclear double resonance (ENDOR) spectroscopy of ${ }^{2} \mathrm{HMoCO}^{+}$shows a signal which simulations show to have a hyperfine tensor with an isotropic coupling, $\mathrm{a}_{\mathrm{iso}}\left({ }^{2} \mathrm{H}\right)=-0.22 \mathrm{MHz}$, and a roughly dipolar anisotropic interaction, $\mathbf{T}\left({ }^{2} \mathrm{H}\right)=[-0.48,-0.93,1.42] \mathrm{MHz}$. The simulations show that the deuteron is bound to $\mathrm{N}_{\mathrm{am}}$, near the Mo equatorial plane, not along the normal, and at a distance of $2.6 \AA$ from Mo, which is nearly identical to the $\left(\mathrm{N}_{\mathrm{am}}\right)^{2} \mathrm{H}^{+}$-Mo distance predicted by DFT computations.

Molybdenum complexes of the $[\mathrm{L}]=\left[\mathrm{HIPTN}{ }_{3} \mathrm{~N}\right]^{3-}$ ligand $(\mathrm{HIPT}=3,5-(2,4,6-$

$\left.{ }_{i} \mathrm{Pr}_{3} \mathrm{C}_{6} \mathrm{H}_{2}\right)_{2} \mathrm{C}_{6} \mathrm{H}_{3}$ ) catalytically reduce dinitrogen to ammonia under mild conditions. 1 The mechanism proposed for this process, a stepwise addition of proton/electron pairs, rests on the intermediate states that have been isolated and characterized to date. However, the mechanism by which the first proton/electron pair converts $\mathbf{M o N}_{2}(\mathbf{M o}=[\mathrm{L}] \mathrm{Mo})$ into Mo$\mathrm{N}=\mathrm{NH}(\mathrm{MoNNH})$ is unknown. This transformation occurs rapidly in the presence of a reductant, $\mathrm{CoCp}_{2}$ or $\mathrm{CrCp}_{2}$, and any one of the acids [ $\left.\mathrm{Et}_{3} \mathrm{NH}\right][\mathrm{OTf}],\left[\mathrm{Et}_{3} \mathrm{NH}\right]\left[\mathrm{BAr}_{4}\right]$, or [2,6-LutH] $\left[\mathrm{BAr}_{4}\right]$. Three mechanistic routes have been considered: (i) reduction followed by protonation, either at $\mathrm{N}_{\beta}$ on the dinitrogen ligand or an amido $\mathrm{N}\left(\mathrm{N}_{\mathrm{am}}\right)$ of [L]; (ii) protonation of either type of nitrogen, followed by reduction; (iii) or proton-coupled electron transfer, again with alternate sites for the proton. To achieve a comprehensive understanding of the reduction mechanism, it is of importance to identify the site at which a proton is most likely to interact.

In the absence of reducing agent, addition of one equivalent of $\mathrm{LutH}^{+}$to $\mathrm{MoN}_{2}(v(\mathrm{NN})=$ $1990 \mathrm{~cm}^{-1}$ ) generates a new species, $\mathrm{HMoN}_{2}^{+}$, with a $v(\mathrm{NN})$ stretch increased to $2057 \mathrm{~cm}^{-1}$. This shift is consistent with decreased backbonding to the dinitrogen ligand; however, no new low-energy band is observed, as would be expected if $\mathrm{N}_{\beta}$ of the dinitrogen ligand were protonated. Similarly, when MoCO $\left(v(\mathrm{CO})=1885 \mathrm{~cm}^{-1}\right)$ is treated with one equivalent of $\mathrm{LutH}^{+}$, a new species, $\mathrm{HMoCO}^{+}$, appears with $v(\mathrm{CO})$ increased to $1932 \mathrm{~cm}^{-1}, 2$ again

Correspondence to: Richard R. Schrock; Brian M. Hoffman.

Supporting Information Available: This material is available free of charge via the Internet at http://pubs.acs.org. 
because of diminished backbonding. 3 Unfortunately, although the amount of protonated $\mathbf{M o N}_{2}$ increases with the amount of $\mathrm{LutH}^{+}$added, attempts to measure an equilibrium between $\mathrm{MoN}_{2}$ and $\mathrm{HMoN}_{2}{ }^{+}$failed because the complexes undergo concomitant decomposition, 3 most plausibly because loss of protonated $[\mathrm{L}]$ is facile.

As an alternative approach to investigating the site at which a proton interacts with $\mathrm{MoAB}$ $\left(\mathrm{AB}=\mathrm{CO}, \mathrm{N}_{2}\right)$ we have applied EPR and ${ }^{2} \mathrm{H}$ electron-nuclear double resonance (ENDOR) spectroscopy to samples of these MoAB treated with $\mathrm{LutD}^{+}$in the absence of reducing agent.

Treatment of the $\mathrm{S}=1 / 2 \mathrm{MoCO}$ with $\mathrm{LutH} / \mathrm{D}^{+4}$ leads to a new signal in the echo-detected EPR spectrum with a small $g$-spread, $\mathbf{g}=[2.010,1.974,1.953]$ (Fig. S1 and Fig. 1, below), in contrast with that of $\mathrm{MoCO}$, whose $\mathrm{g}$ values are strongly shifted from the free-electron value, $\mathrm{g}_{\|}=3.1, \mathrm{~g}_{\perp}=1.6$, and determined by the Jahn-Teller effect.5 Only a small percentage of the MoCO is converted, consistent with prior results noted above.

We applied pulsed ENDOR spectroscopy 6 to the new species formed by treatment of MoCO with LutD ${ }^{+}$to directly determine the presence and location of a bound deuteron. Mims ENDOR spectra7 taken at multiple fields across the new EPR signal display a doublet pattern centered at the ${ }^{2} \mathrm{H}$ Larmor frequency, with a hyperfine splitting of approximately $\mathrm{A}\left({ }^{2} \mathrm{H}\right) \sim 1 \mathrm{MHz}$ (Fig. 1), corresponding to $\mathrm{A}\left({ }^{1} \mathrm{H}\right)=6.5 \mathrm{MHz}$. The assignment of this signal as a ${ }^{2} \mathrm{H}$ ENDOR response is confirmed by its suppression in a spectrum taken with the spacing between the first and second pulses of the Mims sequence of $\tau=1 \mu \mathrm{s}$. The Mims ENDOR intensity is modulated by the response factor $\mathrm{R} \sim[1-\cos (2 \pi \mathrm{A} \tau)]$. For an $\mathrm{A}=1$ $\mathrm{MHz}$ coupled deuteron, the Mims ENDOR response should be suppressed when $\tau=1 \mu \mathrm{s}$, as observed in the spectrum collected at $\mathrm{g}=1.974$ (Fig. 1 and Fig. S2).

To confirm that the ${ }^{2} \mathrm{H}$ ENDOR response is associated with ${ }^{2} \mathrm{HMoCO}^{+}$and does not arise from the background EPR signal of MoCO, we collected the ENDOR-induced-EPR (EIE) spectrum associated with the ${ }^{2} \mathrm{H}$ signal.7 A 2D field-frequency pattern of ${ }^{2} \mathrm{H}$ ENDOR spectra was collected at multiple points across the range of fields that yield a ${ }^{2} \mathrm{H}$ ENDOR response. The ${ }^{2} \mathrm{H}$ ENDOR signal does not extend past the narrow range of fields assigned to the ${ }^{2} \mathrm{HMoCO}^{+}$EPR signal. A fit of the $v_{+}$peak intensities from the 2D pattern of ENDOR spectra to a spline curve yielded the EIE spectrum of ${ }^{2} \mathrm{HMoCO}^{+}$presented in Fig 1, with gvalues corresponding to those given above.

The $2 \mathrm{D}$ field-frequency ${ }^{2} \mathrm{H}$ ENDOR pattern of Fig. 1 was simulated 8 to determine the hyperfine tensor of the bound deuteron, and through this to obtain insight into its location and chemical environment. The pattern is well simulated by a hyperfine tensor having components $\mathbf{A}\left({ }^{2} \mathrm{H}\right)=[-0.70(10),-1.15(05), 1.2(1)] \mathrm{MHz}$, which is oriented relative to $\mathbf{g}$ by the Euler angles $(\alpha, \beta, \gamma)=(25,65,0) .9$ This interaction corresponds to an isotropic coupling, $\mathrm{a}_{\mathrm{iso}}\left({ }^{2} \mathrm{H}\right)=-0.22 \mathrm{MHz}$, and a roughly dipolar anisotropic interaction, $\mathbf{T}\left({ }^{2} \mathrm{H}\right)=$ $[-0.48,-0.93,1.42] \mathrm{MHz} .10$ To test the assignment of the species being studied as Mo$\mathrm{N}_{\mathrm{am}}\left({ }^{2} \mathrm{H}^{+}\right)$, we performed a DFT optimization on an Nam-protonated MoCO, Fig. 2 and Table 1.11 The low g anisotropy of the new spectrum indicates a strong reduction from the threefold symmetry of the parent MoCO. The DFT geometry optimization of the Namprotonated ${ }^{2} \mathrm{HMoCO}^{+}$is consistent with such a symmetry reduction; the length of the Mo$\mathrm{N}_{\mathrm{am}}\left(\mathrm{H}^{+}\right)$bond is predicted to be approximately $13 \%$ longer than the Mo- $\mathrm{N}_{\mathrm{am}}$. This reduction from three-fold symmetry at Mo readily accounts for the suppression of JT effects implied by the small g anisotropy. If, instead, the oxygen of the axial $\mathrm{CO}$ were protonated, DFT computations (Fig. 2 and Table 1) indicate that the resultant species very nearly retains the trigonal symmetry of the parent. Such a complex would exhibit large g anisotropy, like that of MoCO, and contrary to observation. 
The observed hyperfine tensor also is consistent with $\mathrm{N}_{\mathrm{am}}$-protonation. Taking the experimental $\mathrm{T}_{3}=1.42 \mathrm{MHz}$ as an effective through-space dipolar coupling constant, $\mathrm{T}_{3}=$ $2 \mathrm{~T}=2 \mathrm{~g}_{\mathrm{e}} \beta_{\mathrm{e}} \mathrm{g}_{\mathrm{n}} \beta_{\mathrm{n}} / \mathrm{r}^{3}$, gives $\mathrm{r}=2.6 \AA$, consistent with that predicted for a point-dipole interaction between the Mo spin and $\mathrm{N}^{2} \mathrm{H}^{+}$at the distance calculated from the DFT geometry optimization $(2.7 \AA$, Table 1$), 2 \mathrm{~T}=1.26 \mathrm{MHz} .12 \mathrm{In}$ contrast, for protonation at the carbonyl oxygen, the DFT geometry gives $\mathrm{r} \sim 3.65 \AA$, with $2 \mathrm{~T} \sim 0.50 \mathrm{MHz}$, much smaller than observed. More importantly, perhaps, the $\mathrm{Mo}^{-2} \mathrm{H}^{+}$vector for $\mathrm{CO}$ protonation would lie roughly along the $\mathrm{g}_{1}$ direction, $\beta \sim 13^{\circ}$, whereas the $\mathrm{Mo}^{2} \mathrm{H}$ vector for $\mathrm{N}_{\mathrm{am}}$-protonation lies at $\beta=88^{\circ}$, in acceptable agreement with the simulations, $\beta=65^{\circ}$. In short, both the $\mathbf{g}$ tensor and ${ }^{2} \mathrm{H}$ hyperfine tensor are in agreement with $\mathrm{N}_{\mathrm{am}}$-protonation, and not with $\mathrm{CO}$ protonation. An equivalent argument rules out protonation of the 'distal' axial nitrogen of [L].

The properties of the ${ }^{2} \mathrm{H}$ hyperfine tensor for $\mathrm{N}_{\mathrm{am}}\left({ }^{2} \mathrm{H}^{+}\right)$of the $\mathrm{LutH}^{+}$-treated MoCO complex provide support for our recent assignment of the species trapped in frozen solutions when $\mathrm{MoN}_{2}$ is treated with $\mathrm{H}_{2}$ gas. This species was assigned as the hydrido-Mo(III) anion formed by heterolytic cleavage of $\mathrm{H}_{2}$ and loss of $\mathrm{H}^{+}$. If instead, this species were the neutral complex formed by heterolytic ${ }^{2} \mathrm{H}_{2}$ cleavage, with the proton bound as $\mathrm{N}_{\mathrm{am}}\left(\mathrm{H}^{+}\right)$and the hydride bound to Mo(III), it would necessarily show an ENDOR signal equivalent to that seen here from $\mathrm{N}_{\mathrm{am}}\left({ }^{2} \mathrm{H}^{+}\right)$, but it does not.

We were unsuccessful in trapping the analogous protonated $\mathbf{M o N}_{2}$ at low temperature in an EPR tube, the complex instead presumably decomposing to unidentified species through loss of the protonated organic ligand. Following our earlier discussion of modes of decomposition of the product(s) of reaction of $\mathrm{H}_{2}$ with Mo,13 it seems likely that protonation of $\mathrm{MoN}_{2}$, like protonation of $\mathrm{MoCO}$, occurs at the amido nitrogen, and that the bond between Mo and $\mathrm{N}_{\mathrm{am}}\left(\mathrm{H}^{+}\right)$of amido-protonated $\mathbf{M o N}_{2}$ cleaves to form an 'arm-off' species that is unstable to total ligand loss, possibly through bimolecular processes. An alternative is that dinitrogen is lost from the cationic species more readily than $\mathrm{CO}$ is lost, again with overall decomposition. The same type of frequency change to the N-N and C-O stretches upon treatment of the respective parent species with $\mathrm{LutH}^{+}$suggest that protonation occurs at the same site in both systems.

In summary, a combination of EPR/ENDOR spectroscopy and DFT computations shows that treatment of $\mathrm{MoCO}$ with the acid $\mathrm{LutH}^{+}$results in protonation of the amido nitrogen of the $\mathrm{HIPTN}_{3} \mathrm{~N}^{3-}$ ligand. Infrared spectroscopic measurements show that $\mathbf{M o C O}$ and $\mathbf{M o N}_{2}$ behave similarly when treated with $\mathrm{LutH}^{+}$in the absence of reductant, which strongly suggests that $\mathrm{N}_{\mathrm{am}}$ is protonated in the same way, although protonated $\mathbf{M o N}_{2}$ is too unstable to be trapped for EPR/ENDOR analysis. That $\mathrm{N}_{\mathrm{am}}$ is the site of protonation for MoAB, $\mathrm{AB}$ $=\mathrm{CO}$ and $\mathrm{N}_{2}$, further indicates that when acid and reductant are both present, then reduction of $\mathrm{MoN}_{2}$ proceeds either by protonation of Nam followed by electron transfer or by protoncoupled electron transfer. This finding also provide evidence for $\mathrm{N}_{\mathrm{am}}$-protonation as the first step in the acid-induced decomposition of $\left[\mathrm{HIPTN}_{3} \mathrm{~N}\right] \mathrm{Mo}(\mathrm{III}) \mathrm{N}_{2}$.

\section{Supplementary Material}

Refer to Web version on PubMed Central for supplementary material.

\section{Acknowledgments}

This work was supported by the NIH (HL13531, BMH; GM31978, RRS; GM067349, RLM) and NSF (MCB0316038, BMH). 


\section{References}

1. Yandulov DV, Schrock RR. Science (Washington, DC, U S). 2003; 301:76-78.

2. We have been unable to identify any features in the IR spectrum of MoAB AB $=\mathrm{CO}$ or $\mathrm{N} 2$ treated with $\mathrm{LutH}+$ that are consistent with a new NH stretch.

3. Schrock RR. Angew Chem, Int Ed. 2008; 47:5512-5522.

4. A $5 \mathrm{mM}$ solution of $\mathrm{MoCO}$ in toluene was treated with one equivalent of $\left[2,4,6-\mathrm{Me}_{3} \mathrm{C}_{5} \mathrm{H}_{3} \mathrm{~N}\right] \mathrm{BAr}{ }_{4}$ at room temperature and stirred. Solutions of protonated $\mathrm{MoN}_{2}$ were generated likewise.

5. McNaughton RL, Roemelt M, Chin JM, Schrock RR, Neese F, Hoffman BM. J Am Chem Soc. 2010; 132:8645-8656. [PubMed: 20429559]

6. Davoust CE, Doan PE, Hoffman BM. J Magn Reson. 1996; 119:38-44.

7. Schweiger, A.; Jeschke, G. Principles of Pulse Electron Paramagnetic Resonance. Oxford University Press; Oxford, UK: 2001.

8. Doan, PE. The Past, Present, and Future of Orientation-Selected ENDOR Analysis: Solving the Challenges of Dipolar-Coupled Nuclei. In: Telser, J., editor. Paramagnetic Resonance of Metallobiomolecules. American Chemical Society; 2003. p. 55-81.

9. The quadrupole splitting for the deuteron is not resolved in the ENDOR spectra, but its incorporation into the simulations is necessary to obtain quality fits. From the simulations we predict principal values of $\mathrm{P}=[-0.075,0.034,0.039] \mathrm{MHz}$, with an orientation relative to $\mathrm{g}$ of (a, $\beta, ?)=(0,55,0)$.

10. The isotropic and dipolar hyperfine couplings are calculated from the expression $\mathrm{A}=\mathrm{aiso} 1+\mathrm{T}$. Absolute signs for the principal hyperfine values were not directly determined. Rather, the sign of aiso is expected to be negative because spin polarization to this proton should be indirect through the Nam nucleus.

11. Density Functional Theory (DFT) calculations were performed with the Amsterdam Density Functional (ADF) software package (ADF version 2007.01, SCM, Theoretical Chemistry, Vrije Universiteit, Amsterdam, The Netherlands, http://www.scm.com) with a BLYP functional in the spin-unrestricted formalism. Geometry optimizations used a TZ2P basis set with a small core potential for all atoms. A reduced structure for Mo in which the HIPT groups were replaced with phenyls was used for the geometry optimizations.

12. Snetsinger PA, Chasteen ND, van Willigen H. J Am Chem Soc. 1990; 112:8155-8160.

13. Kinney RA, Hetterscheid DGH, Hanna BS, Schrock RR, Hoffman BM. Inorg Chem (Washington, DC, U S). 2010; 49:704-713. 


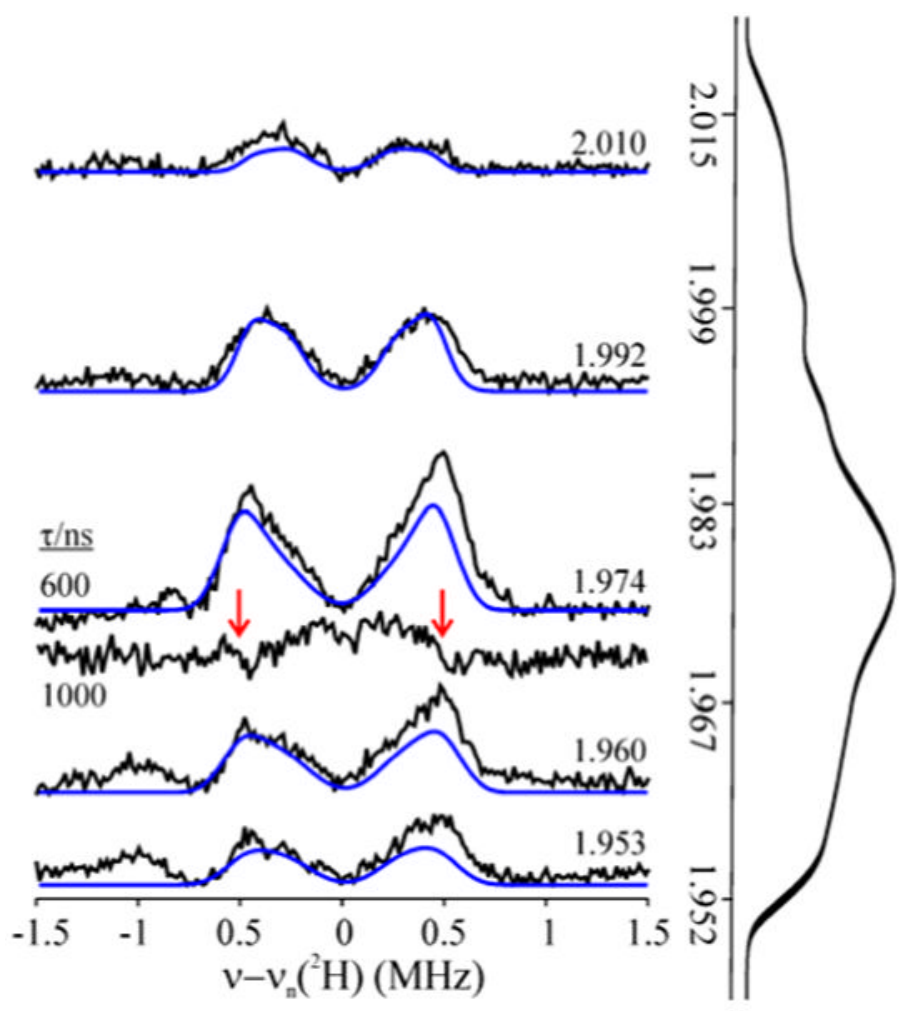

Figure 1.

$35 \mathrm{GHz}$ Mims ${ }^{2} \mathrm{H}$ ENDOR field-frequency pattern for ${ }^{2} \mathrm{HMoCO}^{+}: \mathbf{A}=[-0.70,-1.15,1.2]$ $\mathrm{MHz}$; orientation relative to $\mathbf{g},(\alpha, \beta, \gamma)=(25,65,0)$. Hyperfine suppression holes are indicated with red arrows for the $\tau=1000 \mathrm{~ns}$ spectrum taken at $\mathrm{g}=1.974$. The ENDORinduced-EPR spectrum was generated by plotting the intensity of the $v_{+}{ }^{2} \mathrm{H}$ ENDOR response versus field, then applying a spline fit to the data. 


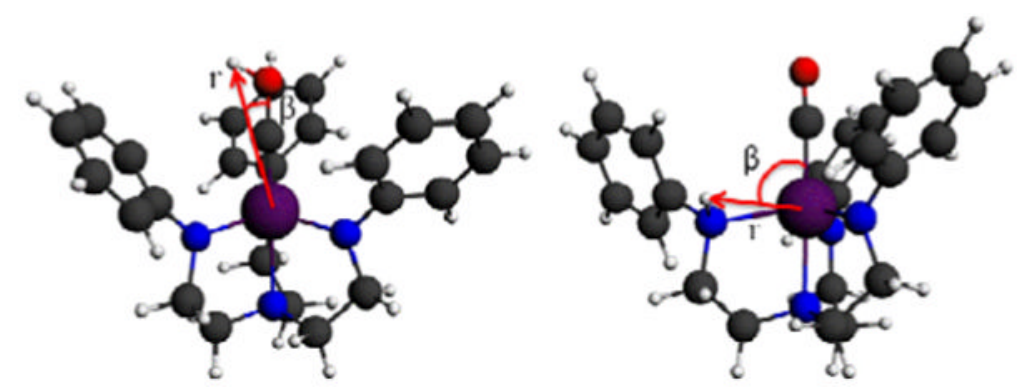

Figure 2.

DFT optimized structures for CO-protonated (left) $\mathrm{N}_{\mathrm{am}}$-protonated (right) MoCO. The predicted values of $\mathrm{r}, \beta$ are $3.65 \AA, 13^{\circ}$ for the CO-proton, and $2.7 \AA, 88^{\circ}$ for the $\mathrm{N}_{\mathrm{am}}$-proton ( $\mathrm{g}_{1}$ is expected to be nearly coincident with the MoC bond axis). 


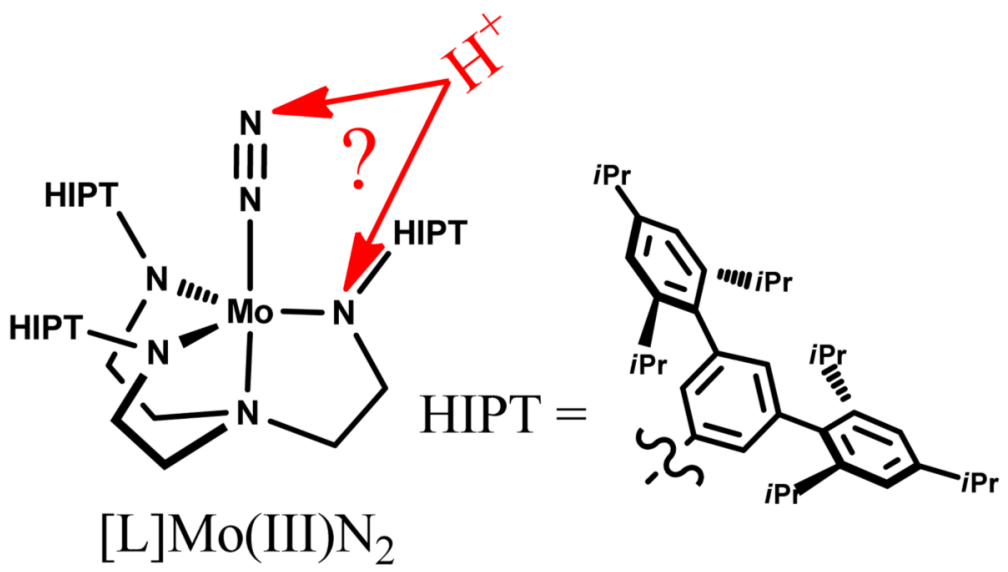

Scheme 1. 


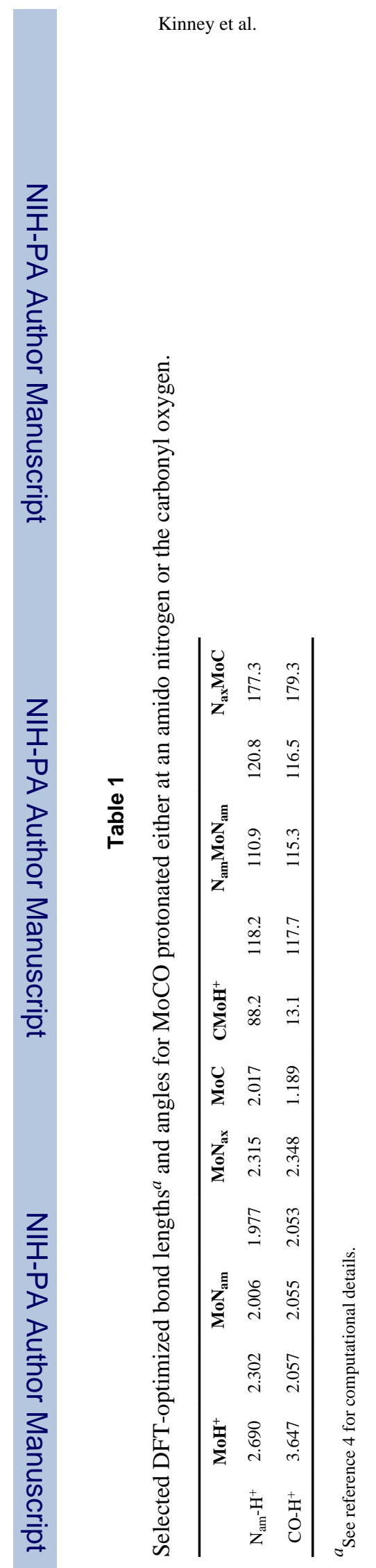

Inorg Chem. Author manuscript; available in PMC 2012 June 14. 